\title{
Airplane headache: a further case report of a young man
}

\author{
Izabela Domitrz
}

Received: 21 May 2010/Accepted: 12 July 2010/Published online: 6 August 2010

(C) Springer-Verlag 2010

\begin{abstract}
Headache with normal examinations and imaging, occurring during an airplane flight has been rarely reported. We present a young patient with a new type of headache that appeared during flights: take-off and landing of a plane and was not associated with other conditions. This airplane headache is rather rare in population and the pathophysiology of this type is not clear. Secondary causes must be ruled out before the diagnosis of a primary headache is made.
\end{abstract}

Keywords Airplane headache .

Flight-associated headache $\cdot$ Altitude headache

\section{Introduction}

Headache with normal examinations and imaging, occurring during take-off and descent of an airplane has been rarely reported. The pathophysiology of this airplane headache is unclear. It has been proposed that barotrauma associated with altitude variations caused changes activating the trigeminovascular system. Altitude headache is a known symptom of high-altitude exposure and it is recognised as a secondary-type headache in the second edition of the International Classification of Headache Disorders (ICHD-II) [1]. Airplane headache has not been recognized in ICHD-II. This is characteristic the fact, that pain appears during altitude variations (take-off and landing), is the hallmark of airplane headache, distinguishing it

\footnotetext{
I. Domitrz $(\bowtie)$

Department of Neurology, Medical University,

1a Banacha Street, 02-097 Warsaw, Poland

e-mail: izabela.domitrz@wum.edu.pl
}

from altitudinal headache or any other form of primary headache that might appear during an airplane flight. A total of 14 case reports of this new type of headache have been published so far [2-8]. We present a patient with a history of a headache associated with airplane travel, and according to the literature, we diagnose him with airplane headache.

\section{Case report}

A 29-year-old healthy man, who works as a psychologist, reported that during his last airplane journey, he developed a very severe and sudden jabbing headache located in the left frontal region with radiation into the left eye. It started during take-off, diminished during the 2-h flight, a very mild pain was present during the flight and increased during plane's descent and lasted until a few minutes after landing. Then, the pain completely and spontaneously subsided. The same situation took place 3 days later when the patient was returning. He remembers that he had similar, but milder headaches during previous flights. However, they occurred only during airplane flights and did not develop during jumbo jet flights. Similar headache did not appear in other altitude variation moments, e.g. in mountain trips.

The pain was always located in the left frontal region with radiation into the left eye without any autonomic symptoms and neurological focal problems. He could not move until the headache disappeared. The patient has no medical history of sinus problems and using any medications. The family history has shown only tension type headache in patient's 4 years older sister. General (including blood pressure and heart rate), neurological, otolaryngological and ophthalmological examinations were 
normal. Brain magnetic resonance imaging also with angiography excluded any structural lesions and arterial malformations.

\section{Discussion}

Several case reports published recently introduced a new form of headache called "airplane headache" that appeared during flights [2-8] that type of headache is not associated with other disorders and occurred during flights.

The presented case is the next example of a headache related to an airplane journey, but not a jumbo jet journey. The described pain has the same characteristics in the majority of cases published recently and fulfils the criteria proposed for classification [8]. Mainardi et al. [8] proposed criteria to diagnose "airplane headache": at least two attacks of unilateral pain in periorbital location with severe intensity and jabbing or stabbing quality during airplane travel lasting for $20 \mathrm{~min}$, without any accompanying symptoms and not attributed to other pathologies. A mild pain during the airplane trip does not exclude the diagnosis.

Most of the known cases of airplane headache are young male cases, as in our patient.

Evans et al. [5] stated that migraine may be triggered by airplane travel and on the other hand secondary aetiologies of "airplane headache" have also been reported [9].

Our patient had not had a history of migraine or cluster headache and he had not any accompanying symptoms. His general, neurological, ophthalmological and otolaryngological examination, brain MRI and angio-MRI were normal. His distribution and intensity of pain were characteristic of airplane headache, although his headache lasted until the plane landed, but significantly decreased during the flight. It is puzzling that our patient suffers from headache during an airplane journey, but not during a jumbo jet journey. May be it is connected with different air pressure inside a particular type of a plane determined by an altitude. Although the hypothesis of a barotrauma is one of the possible explanation, but relation with the rapid changes in the cabin pressure during take-off and landing uncertain.

It seems that "airplane headache" might be given to include in the International Headache Society Classification of Headaches III edition, as a headache type for future study.

This type of headache seems to be infrequent in comparison to other types of headaches that may be induced by airplane travel [9].

Conflict of interest None.

\section{References}

1. (2004) The International Classification of Headache Disorders. 2nd edn. Cephalalgia 24(1):107-108

2. Coutinho E, Pereira-Monteiro J (2008) "Bad trips": airplane headache not just in airplanes? Cephalalgia 28:986-987

3. Atkonson V, Lee L (2004) An unusual case of an airplane headache. Headache 44:438-439

4. Berilgen MS, Müngen B (2006) Headache associated with airplane travel: report of six cases. Cephalalgia 26:707-711

5. Evans RW, Purdy A, Goodman SH (2007) Airplane descent headaches. Headache 47:719-723

6. Marchioretto F, Mainardi F, Zanchin G (2008) Airplane headache: a neurologist's personal experience. Cephalalgia 28:101

7. Leon-Sarmiento FE (2008) Airplane headaches: time to classify them. Headache 48(1):165-166

8. Mainardi F, Lisotto C, Palestini C, Sarchielli P, Maggioni F, Zanchin G (2007) Headache attributed to airplane travel ('airplane headache'): first Italian case. J Headache Pain 8:196-199

9. Potsman I, Rofe O, Weller B (2008) Flight-associated headachesprevalence and characteristics. Cephalalgia 28:863-867 